\title{
Developing the Elderly Tourism Market in China
}

\author{
Shijun $\mathrm{Wu}^{1}$, Zhaoyue Wang ${ }^{1}$, Nikki Wingate ${ }^{2}$, and Haitao Guo ${ }^{1}$ \\ ${ }^{1}$ Management School of Wuhan Science and Technology University, Wuhan 430081, China \\ ${ }^{2}$ Assistant Professor and Department Chair of Marketing Ernest C. Trefz School of Business, University of Bridgeport, Bridgeport \\ CT 06604 USA
}

\begin{abstract}
With a rapidly growing number of the elderly in the population, the consumption level of the elderly continuously improves to afford travel. Consequently, the elderly tourism industry faces unprecedented opportunities. The aim of this study was to promote the healthy development of the elderly tourism market in China. We provide practical suggestions for providers of senior tourism products and services, in addition to proposing a new way to build a favorable environment for senior tourism industry. Based on the comprehensive literature review on the consumption of senior tourism, we incorporate the marketing strategy of $4 \mathrm{C}$ into specifying recommendations that will promote the development of the senior tourism industry. Our recommendations will motivate the healthy development of our country's senior tourism industry in four aspects of product, cost, convenience and communication.
\end{abstract}

Keywords-aging population; tourism industry; senior consumption; elderly consumers; market analysis

\section{INTRODUCTION}

The 2015 census data in China displays that the national population exceeds the number of 1.37 billion, of which 212.42 million are aged 60 or older, constituting $15.5 \%$ of the total population. Of those, 137.55 million are people who are at least 65 years old, accounting for $10.1 \%$ of the total population. China is the world's first country whose aging population has reached 100 million, entering a phase where rapid growth is expected. By 2035, the proportion of the aging population in China will jump to $20 \%$ of the total population. By 2020, China's total aging population aged 60 or older is estimated to achieve 0.248 billion, and 0.4 billion by 2050 . China, therefore, will become a country with a substantial proportion of senior citizens in the population. According to the data on the National Bureau of Statistics of the People's Republic of China, the total number of China's domestic visitors and the total cost of tourism are respectively 5.24 million people and 102.3 billion yuan in 1994, while in 2014 these numbers will respectively reach 36.11 million people and 3031.186 billion yuan, which illustrates that China's tourism shows stable development growth and achieves remarkable accomplishments. The tourism industry has consistently developed to claim an increasingly important status in the national economy in China. Given this environment, it is imperative to conduct research on the specific sector of the tourism industry targeting senior citizens or the elderly consumers in China.

\section{LITERATURE REVIEW}

\section{A. Foreign literature on segmentation of elderly tourists}

As the western world has entered the aging society earlier than China, the scholars in the West have conducted the research on the related aspects of an aging population, including research on the tourism industry targeting elderly consumers. As one of the early western scholars on the relevant research of the elderly people's tourism market, Shoemaker discussed the tourism pattern, attitude and motivation of the tourists as consumers and proposed classifying the elderly tourist market into three market segments of family tourists, active leisure seekers, and the elderly tourists (Shoemaker, 1989). He used cluster analysis based on consumer motivation in the tourist market [1]. A decade later, Shoemaker (2000) repeated the research using the elderly tourists (age 55 or over) as his sample and proposed using the travel motivation to classify the elderly tourism market into three market segments: those who want to escape and study, the retirees, and the active relater [2]. Selliek (2004) suggested that the elderly tourism market could be divided into four market segments: those who seek exploration and self-improvement, those who seek emotional exchange, stubborn tourists, and nostalgic tourists. He concluded that nostalgia was the most powerful motivation, as nostalgic tourists manifested as the largest segment in the elderly tourism market [3].

To sum up, the literature shows the focus on the primary need to segment the elderly tourist market using various types of motivation of the elderly tourists. Consistent with the literature, we propose classifying the Chinese elderly tourist market using the purpose of tourism as the segmentation criterion, which will produce the following market segments: sightseeing, visiting relatives, health maintenance, seeking nostalgia, social activity, and realizing the dreams.

\section{B. Chinese literature on elderly tourists}

Chinese researchers conduct the relevant research on the aging at the macro level, in various aspects of economy, society, culture and politics, etc. This article primarily focuses on the marketing discipline to examine relevant literature of the elderly tourism market in China. The current status and the characteristics of the elderly tourism market in China are as follows. The elderly tourists strongly prefer travel, regard pure travel activities as the sole purpose of travel, enjoy group 
activities with significant other ("the other half"), and prefer the natural scenery and traditional culture (Chen, 2006) [4]. China's elderly tourism market has four characteristics: firstly, high growth rate of market and strong geographical focus; secondly, strong purchasing potential and high tourism demand thirdly, most elderly tourists focus on the slow travel and enjoy the leisure health; fourthly, they have liberal travel time and prefer to travel during the off season (Liu, 2011) [5]. The consumption of the Chinese elderly consumers has four characteristics of frugality, habituation, intellect and obstinacy (Jiang, 2014) [6].

The literature on the Chinese elderly tourists appears to have focused primarily on deliberating particular aspects of the current situation and specifying characteristics of the elderly market. Other topics mentioned include product development of the elderly tourism, consumption behavior, and market development countermeasures, etc. Most researchers have employed qualitative analyses, while the researches utilizing quantitative analyses tend to conduct the investigation of the elderly tourist consumers by geographic areas, for example, certain specific cities.

\section{ThE CURRENT CONTEXT OF CHINA'S TOURISM MARKET WITH AN AGING POPULATION}

\section{A. Status on China's aging population}

The international standards refers to the elderly as one who is over 60 years old. The country (or the region) will enter the aging society if its population of those 60 and older exceeds $10 \%$ of its total population, or if its population of those older than 65 years reaches $7 \%$ of its total population. According to reports of the 2015 census, the proportion of the elderly population in China is projected to continue growing rapidly, at about 3 percent per year. As indicated in Table 1, the total elderly population will reach to 292.40 million by 2050 , when the proportion of the elderly population will reach $20.62 \%$ of the total population. This trend corroborates the substantial need for preparing for any potential negative consequences of having an aging population.

TABLE I. ForecAst OF THE AGE STRUCTURE OF CHINA's POPULATION (UNIT: TEN THOUSAND PEOPLE)

\begin{tabular}{|c|c|c|c|c|c|c|}
\hline \multirow{3}{*}{ year } & \multicolumn{6}{|c|}{ Classified by age group } \\
\hline & \multicolumn{2}{|c|}{0 -14 years old } & \multicolumn{2}{|c|}{ 15-64 years old } & \multicolumn{2}{|c|}{65 years old and the above } \\
\hline & Population & Proportion $(\%)$ & Population & Proportion $(\%)$ & Population & Proportion (\%) \\
\hline 2010 & 22259 & 16.60 & 99938 & 74.50 & 11894 & 8.90 \\
\hline 2020 & 27785 & 19.30 & 99696 & 69.26 & 16474 & 11.44 \\
\hline 2030 & 25869 & 17.57 & 98785 & 67.09 & 22586 & 15.34 \\
\hline 2040 & 24179 & 16.51 & 92893 & 63.43 & 29378 & 20.06 \\
\hline 2050 & 23102 & 16.08 & 98481 & 63.09 & 29240 & 20.62 \\
\hline
\end{tabular}

B. Current problems in the elderly tourism industry in China

The elderly tourism industry in China is still at the incipient stage of the development; the development of the elderly tourist market is not mature either. At present, a number of problems exist in the elderly tourist market in China:

Firstly, the discrepancy between supply and demand in the elderly tourism market is exacerbating. Currently Chinese elderly tourism consumer market exhibits the characteristics of low profit, high demand, high risk, high cost and low income. This, in turn, leads to rampant and prevalent misconceptions about the elderly tourism market and suppressing the development of elderly tourism market. It then produces a shortage of products and services in the elderly tourism industry, creating the imbalance between supply and demand.

Secondly, pertinence of products and services is in need. It is undeniable that the elderly tourists have different life experiences, physical conditions, education level, and family situation, etc. Therefore, it is necessary for the participants of the elderly tourism consumer market to conduct the relevant research analysis which can develop the tourism products that can meet the requirements of the complex combination of physiological, demographic, psychological, and behavioral features of the elderly tourists.
Thirdly, management of the elderly tourism is unstandardized and unregulated. Exact details of the legal restrictions or guidance pertaining to the elderly tourism are not yet completely transparent. Some personnel in the related governmental departments lack authority to enforce laws that can standardize the order of the elderly tourism industry. Several practitioners within the elderly tourism industry frequently appear unethical. Driven by self-centered interests, they deceive elderly tourists and disrupt the normal order of the tourism market. Such irregularities do not contribute to the long-term development of the elderly tourist industry.

IV. The 4C Marketing Strategy to Promote the DEVELOPMENT OF THE ELDERLY TOURIST INDUSTRY

\section{A. Providing products and services which can meet the requirements and desires of the elderly tourists (Consumer)}

After analyzing the travel demands of the elderly in Shanghai, Gu Xiaoling and Yu Haiqin (2012) proposed that the travel demands of the elderly primarily include the three aspects of the spiritual demand, fitness and social demands, and physiological needs [7]. Consistent with Maslow's Needhierarchy Theory, as well as Gu and $\mathrm{Yu}$ (2012), we believe that the demands of the elderly tourists most often include the following six aspects: physiological and security needs, social needs, esteem needs, health care and recuperation needs, nostalgia needs, and self-actualization needs. We elaborate each in more detail. 


\section{1) Adapt to their particularity and satisfy their} physiological and safety requirements.

The physiological status of the elderly tourists is different from that of the young tourists. They are often frail and their physical strength is weak. They don't like crowded areas or congestion. They often have poor quality of sleep and the function of the digestive system weakens. Considering these particular characteristics regarding their physiological status, the tourist products should be adapted to the characteristics of the elderly population. In the aspect of food and beverage services, marketing communications should emphasize fragrance, crispiness, and softness of the food. A special attention should be paid to cleanliness of the surrounding environment. In the aspect of services that accommodate their sleep, marketers should try their best to provide a quiet and tastefully decorated environment with least disturbances. Moreover, patient and considerate service in order to satisfy the elderly consumers' need for security is required. In the aspect of the transportation services, marketers should emphasize security and comfort as main points of communication. Transportation vehicles should be regularly maintained and necessary repairs must be completed in timely manner. Travel agencies must demonstrate high quality service by understanding and adapting to the daily habits of the elderly consumers.

\section{2) To satisfy social needs regarding hobbies and interests}

After retirement, the elderly consumers will often feel idle and lonely, therefore satisfying their social needs occupies an important place. Travel agencies can promote distinctive travel products related to the elderly consumer's hobbies and interests in order to help the elderly tourists make new friends with the like-minded companions. Travel products can engender social satisfaction in performing together such activities as singing, lyre-playing, chess, calligraphy, and painting activities during the trip.

3) Respect and cherish the elderly to satisfy their respecting demands

The elderly tourists tend to need more concern and care during the journey, thereby requiring service personnel with good professional quality to provide thoughtful service so as to achieve the goal of letting the elderly tourists know that they are respected and cherished. Especially the guide should not only possess basic requirements of professional knowledge, strong communication capability, sense of responsibility, but also understand the mentality of the elderly tourist in order to develop and maintain close-knit relationship with the elderly tourist.

4) Emphasize beneficial effects of prolonged life and satisfy their health care needs

The elderly consumers pay much attention to the information relevant to their health care in their daily life. They are eager to receive health care treatments to not only recuperate from illness but also achieve the goal of continued health care. Moreover, the current environmental quality in China is not high; therefore the elderly tourists often seek places with fresh air and plenty of sunshine to enhance their well-being. Travel agencies can target these elderly consumers to develop or add to the existing travel products new projects such as 'health care tour' and 'rehabilitation tour' to satisfy the health care needs of the elderly tourists.

5) Provide thematic travel to satisfy their nostalgia needs

One significant characteristic of the elderly consumers is that they frequently reminisce in the past and yearn for the past, due to the loneliness. Often, they may take a significant amount of time for nostalgia. They recall with remarkable detail and accuracy. They recall their own hometowns, where they went, what they did, what interesting things they saw, and so on. These recollections could prompt the elderly consumers with urges to return and travel. Travel agencies should make special thematic travel products for the elderly consumers to enjoy, such as 'nostalgia tour' and 'old haunt tour.'

6) Pay attention to compensate for the regret and satisfy the self-actualization needs to realize their dreams

Due to the limitation of time and money, everyone may experience regret at one time or another. The elderly consumer feels the same, if not more. The elderly consumers have more time at hand with less economic pressure will experience the self-actualization need to realize their dreams, if their physical qualifications allow. They will find opportunities to compensate for the foregone opportunities of the past and fulfill desires they couldn't realize before. Travel agencies can aid in this process by introducing the travel of realizing dreams. For example, develop "Xi Yanghong realizing dream travel of the capital" for the elderly tourists who wish to tour the capital city, and develop the travel route of the "Golden and Silver wedding memorial travel" in order to compensate for the elderly couples who married many years ago and with much regret.

\section{B. Price with the cost the elderly tourists are willing to pay (Cost)}

The Chinese traditional virtue of being thrifty heavily influences elderly tourists. It is unlikely for the elderly to purchase expensive travel products. Attractive in both price and quality is the preferred choice of elderly tourists. The general principle of the price strategy of the travel products targeting the elderly is to adopt the lower price with guarantees of the quality.

The tourism industry is cyclical, with the off season and the peak season. Tickets of famous attractions during the peak season will be more expensive than those during the off season. Moreover, there will be differences in travel service fees, such as airfare and accommodations. Noting that elderly tourists have time to travel all year round, travel agencies can implement the floating or dynamic pricing strategy when dealing with prospective elderly travelers. Travel agencies can attract the price-sensitive elderly consumers to utilize the off season's travel products and make them feel smart for saving money. At the same time, travel agencies can make more specific provisions for the elderly travelers and offer optional and distinctive supplementary services for specifically targeted consumers. Prices of the supplementary services can properly be raised depending on the particulars of quantity, variety, and acceptability of the target consumer in order to ensure its profit margin. 


\section{Provide convenience for the elderly tourists to purchase and use (Convenience)}

Marketers must first provide convenience for easily acquiring the product and service information. The information acquisition channel of the elderly tourists is relatively simple. There are mainly three channels. Firstly, the tourist information is obtained from the acquaintance of relatives, friends and colleagues; Secondly, travel information is obtained through the travel agencies and their distribution brochures; lastly, travel information can also be obtained through major media outlets such as television stations and newspapers, etc. Of these, travel agency is the main channel for obtaining tourist information. The agencies should provide warm service and recommend flexible and diversified travel products for the elderly. The material should be simple and unambiguous in order to help the elderly understand information more easily.

Secondly, marketers should provide convenience for purchasing products and services. Purchase convenience can increase satisfaction of the elderly tourists. Travel agencies can set up office checkpoints to provide opportunities for the elderly to easily purchase travel products. These checkpoints should be set up where the elderly tourists gather. Agencies can offer bundle packages including the cost of accommodation as well as the one-time fee for contract and handling of the procedure. Marketers furthermore can provide the door-to-door service for the intended elderly people.

Thirdly, marketers should provide convenience of consuming products and services. On the one hand, the route through which the travel agency makes arrangements needs to be appropriate. It is not suitable to visit too many scenic spots every day during the course of travel. It is necessary to arrange the rest and adjustment time for the elderly and provide professional medical assistance in order to provide timely treatment when the elderly experience discomfort. On the other hand, tour guides should provide professional services and the explanation of the scenic spots should be relevant to the audience. Guides should be equipped to offer reasonable answers to questions raised by the elderly during the tour.

\section{Facilitate effective bilateral communications with the elderly travelers (Communication)}

In the past, the traditional sense of promotional strategy referred to the consumer as passively accepting the one-way or unilateral communications from businesses. In contrast, the $4 \mathrm{C}$ strategy emphasizes the two-way or bilateral communications, where businesses and consumers achieve their respective goals in communication. Developing the elderly tourism consumer market requires constant communications with the elderly tourists. Effective bilateral communications provide the elderly tourists with information on products, services and prices pertinent to tourism. At the same time, a desirable corporate image can be established via effective communications. In addition, bilateral communications can help realize the changes of the market needs of the elderly in order to renew and innovate tourist products.

Most of the elderly prefer to gather at parks, Elderly Activity Center, and the university for the elderly. Travel agencies can set up the elderly travel service stations and conduct the activity of travel consultation in order to establish the customer needs information system and deliver the travelrelated service information of the travel agency. Agencies can hold the activities within the community with the cooperation of Elderly Activity Center. Examples include exhibitions of the elderly paintings, calligraphy, or photography, and etc. All of these events can have connections with the travel to promote and familiarize the concept of the elderly consumers traveling and awaken the awareness of the elderly in regards to tourism. In keeping with the tradition of filial piety, travel agencies can promote the children to travel with their parents, especially at the special festivals such as Double Ninth Festival and Mother's Day, and design a number of projects for "Family Tourism Packages."

\section{SUMMARY}

Based on the extant literature of the elderly tourism market, authors of this paper conducted the 4C marketing strategy analysis with the marketing perspective of providing practical recommendations for participants of the elderly tourism industry. Recommendations contribute to the development of the elderly tourism consumer industry at the state level.

\section{Acknowledgment}

Research Center of Industrial Policy and Management which is the key research base of the humanistic and social science of Hubei Colleges and Universities (No.CY20150215); Xia Chao Foundation of Taiwan.

Wu Shijun, male, born in June 1974, Xiangxiang city of Hunan Province, associate professor, tutor of Postgraduate student, director of Marketing and E-Commerce department.

The major research directions are Industrial Marketing, Consumer Behavior, and Risk Management.

\section{E-mail: 13667118569@163.com}

Wang Zhaoyue, female, master.

The major research direction is Marketing.

E-mail: 1943933708@qq.com

\section{REFERENCES}

[1] Shoemaker. Segmentation of the Senior Pleasure Traveler Market [J]. Journal of Travel Research, 1989, 27(3): 14 21 .

[2] Shoemaker. Segmenting the mature market: 10 years later [J]. Journal of Travel Research, 2000, 39(1): 11 26.

[3] Megan Cleaver Selliek. Discovery, Connection, Nostalgia: Key Travel Motives within the Senior Market [J]. Journal of Travel \& Tourism Market, 2004, 17(1): 55 71.

[4] Chen Naizhe. Current Situation and Development Channel of The Elderly Tourism Market [J] . Commercial Economic Document, 2006, (1) $: 44 \sim 45$.

[5] Liu Lijun. Research on the Development of China's Elderly Tourism Market [J] . Shi Jiqiao, 2011, (19) : 144 147.

[6] Jiang Liying. The Development and Marketing Strategy of the Elderly Tourism Market[J]. Commercial economy,2014,(8): 3 9

[7] Gu Xiaoling, Yu Haiqin. Analysis and Strategy of Shanghai Yinfa Tourism Market [J]. Tourist economy, 2012, (11) : $190 \sim 191$. 